\title{
Pressure Measurement on the Foreign Exchange Market and Currency Crises in Morocco
}

\author{
ICHOU Mohammed Adil ${ }^{1}$, RASSAM Driss ${ }^{2}$, ABBADI Idriss ${ }^{3}$ \\ and ELHIRI Abderrazak ${ }^{4}$
}

\begin{abstract}
This article aims to assess the pressure upon the official currency of the Kingdom of Morocco - the Dirham - and to detect the periods of crisis on the foreign exchange market. Several methods can be used for this purpose especially the Exchange Market Pressure Index, which is considered as an excellent predictive indicator that takes into account both changes in nominal exchange rate and foreign exchange reserves. In term of results, the pressures on the Moroccan foreign exchange market stem mainly from a substantial decrease in foreign exchange reserves combined with a high deficit of the current account of the balance of payments deficit. In the last part of this article, a logistic model was used to forecast the EMPI for the end of the year 2020. The results of this modeling showed that the pressure on the Moroccan foreign exchange market remained generally under control during the year, although its signs could be felt particularly in the fourth quarter. These results were corroborated by the 2020 officially published figures.
\end{abstract}

Keywords: Foreign exchange market, Exchange Market Pressure Index, Exchange rate, Foreign exchange reserves.

\footnotetext{
${ }^{1}$ PHD student at the FSJES of Fez \& Administration officer at the Ministry of Economy, Finance and Administrative Reform.

${ }^{2}$ PHD student at the FSJES of Ain Sebaa- Casablanca \& Chief Engineer at the Ministry of

Economy, Finance and Administrative Reform.

${ }^{3}$ Professor and Dean of the FSJES of Ain Sebaa- Casablanca.

${ }^{4}$ Professor at the FSJES of Fez.
}

Article Info: Received: January 21, 2021. Revised: March 12, 2021.

Published online: March 16, 2021. 


\section{Introduction}

Since the Bretton Woods collapse, several systemic financial crises have affected the world especially the Mexican peso crisis (1994-1995), the Asian crisis (1997), the mortgage crisis in the United States (2007-2008) and currently the global crisis caused by the unprecedented spread of COVID-19. This is how global financial markets have become more unstable and volatile, leading to more recurrent and deeper crises. Today, currency crises seem to become a global crucial topic in financial systems.

On another side, numerous studies have been carried out to measure the pressure on the foreign exchange market and to identify speculative attacks on the local currencies. In this context, the International Monetary Fund (IMF), as a supervisor and a regulator of the world's economy, defines speculative attacks as a kind of exchange rate crisis that occurs when the national currency is generally at a level far from its equilibrium value. In this scenario, the monetary authorities are forced to intervene by increasing significantly interest rates or injecting huge amounts of foreign currencies into the foreign exchange market to protect the national currencies. For this reason, the IMF has developed an early warning system for foreign exchange crises which includes formal and quantitative tools, notably the Exchange Market Pressure Index (EMPI). This index allows the authorities to provide an appropriate response to alleviate the pressure on the foreign exchange market.

In this perspective, this paper aims to estimate the pressure upon the Moroccan foreign exchange market, over the period from January, 2002 to April, 2020 through the EMPI. It is defined as a weight sum of changes in nominal exchange rate and foreign reserves. The higher the EMPI is, the greater the pressure on foreign currency demand will be. In addition, a country is exposed to a speculative attack when the EMPI exceeds a certain threshold which will be defined later.

This article aims essentially to: (i) describe the methodology for calculating the EMPI and to apply it to the case of Morocco, (ii) assess the probability of a crisis on the foreign exchange market and (iii) anticipate the pressures that could be exerted on this market in the future, particularly in the current economic conditions characterized by the spread of COVID-19. A second distortion index, which will be the subject of the first part, will also be estimated to examine the fluctuations of the exchange rate of the Dirham compared to its equilibrium level (exchange rate misalignment) over the past two decades.

\section{Misalignment of the exchange rate of the Dirham with respect to its equilibrium level \\ 2.1 Objective of the analysis}

The main objective of this part is to estimate the equilibrium real exchange rate of the Dirham over the last two decades, analyzing its evolution and comparing it with the real effective exchange rate (REER). Thus, the purpose is to detect the periods during which it illustrated a "misalignment" over the period 2001-2018. 
Table 1: Misalignment of the REER with respect to its equilibrium level

\begin{tabular}{|c|c|c|}
\hline Periods & $\begin{array}{c}\text { Average } \\
\text { misalignment }\end{array}$ & Conclusion \\
\hline $2001-2002$ & 1,4 & Over-valuation \\
\hline $2003-2007$ & $-1,34$ & Under-valuation \\
\hline $2008-2013$ & 5,2 & Over-valuation \\
\hline $2014-2018$ & $-2,56$ & Under-valuation \\
\hline
\end{tabular}

Source: Authors' calculations

The average gap resulting from the table above between the REER observed and the equilibrium real exchange rate shows positive values which correspond to an overvaluation of the Dirham and negative values which indicate an undervaluation compared to its equilibrium level.

\subsection{Main Results}

The results obtained from the analysis of the time series of the REER and the equilibrium real exchange rate during the period 2001-2018 reveal disparate changes between periods:

$\checkmark$ 2001-2002: Over-valuation at a slow pace which can be explained by the rearrangement, which took place in April 2001, of the Dirham's quotation basket which leads to its depreciation of $5 \%$.

$\checkmark$ 2003-2007: Under-valuation in a period marked particularly by a significant appreciation of the Euro against the Dollar.

$\checkmark$ 2008-2013: Significant over-valuation in a context characterized essentially by a depreciation of the Euro against the Dollar, a widening of the current account deficit and a contraction of foreign assets.

$\checkmark$ 2014-2018: Relatively strong under-valuation which can mainly have its origin in the significant reduction of the twin deficits (fiscal and external) which fell respectively from $7 \%$ and $9.5 \%$ of GDP in 2012 to only $3.7 \%$ and $3.6 \%$ in 2018. The consolidation of the macroeconomic framework, recorded since 2014, has contributed significantly to the stability of the Dirham's fluctuations.

On the other hand, the gap between the REER and the equilibrium real exchange rate, during the first phase of transition to a more flexible exchange rate regime, remains insignificant at around $-1.7 \%$ in 2018 against $-4 \%$ in 2017 . This result shows a relative stability of the Dirham value during the first year which experienced the enlargement of its fluctuation band with a favorable trend towards its equilibrium level. 
This situation is mainly due to:

$\checkmark$ A good performance of foreign direct investments (FDI), which reached 32.8 billion DHS in 2018 for only 26 billion DHS the previous year, a significant increase of almost $26 \%$,

$\checkmark$ The maintaining of the official foreign exchange reserves at a comfortable level covering over 5 months of goods and services' imports,

$\checkmark$ A positive net foreign exchange position of the banks (accounts for 2.7 billion DHS in 2018),

$\checkmark$ The stability of the Treasury debt level, which remains sustainable and under control at around 65\% of GDP, being at a level under a threshold of $70 \%$ considered by the IMF as a red line for emerging countries.

Also, it should be noted that the good practices of foreign exchange market operators have further served the stability of the Dirham value, especially by avoiding non-authorized transactions generating speculation.

\section{Methodology for calculating the EMP crisis index}

The EMPI, used to quantify pressures on a currency, had been a subject of several studies carried out by the IMF on the economies of several countries around the world. Generally, the results of these studies had shown the relevance of this indicator on different adopted exchange rate regimes, be it fixed, flexible or intermediate.

The EMPI is calculated on a monthly basis as a weight sum of both changes in the exchange rate and the foreign exchange reserves.

This index can be either positive or negative: a higher EMPI, reflecting the depreciation of the local currency and/or the decrease in reserves, indicates the presence of increased tensions in foreign exchange market.

Taking into consideration the conceptual bases relating to EMPI and in order to estimate it for the case of our country, a monthly data will be used over the period of January 2002 to February 2020 relating to the nominal exchange rate against the Dollar and the foreign exchange reserves.

\subsection{Definitions}

The formula used for calculating the EMPI was developed by L. Girton and D. Roper (1977) as follows:

$$
\operatorname{EMPI}_{t}=\left(\frac{\mathrm{e}_{\mathrm{t}}-\mathrm{e}_{\mathrm{t}-1}}{\mathrm{e}_{\mathrm{t}-1}}\right) * 100-\left(\frac{\sigma_{\mathrm{e}}}{\sigma_{\mathrm{fxr}}}\right)\left(\frac{\mathrm{fxr}_{\mathrm{t}}-\mathrm{fxr}_{\mathrm{t}-1}}{\mathrm{fxr}_{\mathrm{t}-1}}\right) * 100
$$

Or :

$\operatorname{EMPI}_{\mathrm{t}}=\Delta \mathrm{e}_{\mathrm{t}}-\left(\frac{\sigma_{\mathrm{e}}}{\sigma_{\mathrm{fxr}}}\right) \Delta \mathbf{f x r}_{\mathrm{t}}$ 
Where: $\Delta \mathrm{e}_{\mathrm{t}}$ is the change in nominal exchange rate of the Dirham against the Dollar at time t, $\Delta \mathrm{fxr}_{\mathrm{t}}$ refers to the change in the stock of foreign exchange reserves at time $\mathrm{t}, \frac{\sigma_{\mathrm{e}}}{\sigma_{\mathrm{fxr}}}$ represents the ratio between the standard deviation of changes in both the nominal exchange rate against Dollar and the stock of foreign exchange reserves.

Noting that a high EMPI reflects a situation where there is a strong demand for currencies and then a country is exposed to a speculative attack when this index exceeds its average ( $\mu$ EMP) by at least the double of its standard deviation ( $\sigma \mathrm{EMP})$.

Technically, there is a crisis if: $E M P I_{t}>\mu E M P+\varphi^{*} \sigma E M P \quad$ (critical threshold)

Where: $\varphi$ is a parameter fixed here at the value 2 in accordance with what is applied in practice, which generally takes values between 1.5 and 3 .

Subsequently, a second crisis index is calculated as a binary variable and it takes the following values:

$\checkmark 1$ when the index reaches the critical threshold,

$\checkmark 0$ otherwise.

\subsection{Analysis of the EMP index evolution}

Since the adoption of the exchange rate reform towards a more flexible regime, the foreign exchange reserves had been reconstituted considerably. In fact, they were almost 241 billion Dirhams at the end of the year 2017 and subsequently amounted up to 286.3 billion Dirhams in April17, 2020. This notable improvement is obviously the result of Morocco's successful bond issue on the international financial market, which was concluded with the signing of a loan reaching 1 billion Euros in November 2019, and the withdrawal of \$ 3 million from the IMF through the Precautionary Liquidity Line (PLL) in April 2020.

The line graph below that shows the EMPI evolution makes it possible to identify the different phases of the crisis detected over the above-mentioned period. Particular attention will be drawn to the last two years when Morocco adopted a more flexible exchange regime. 


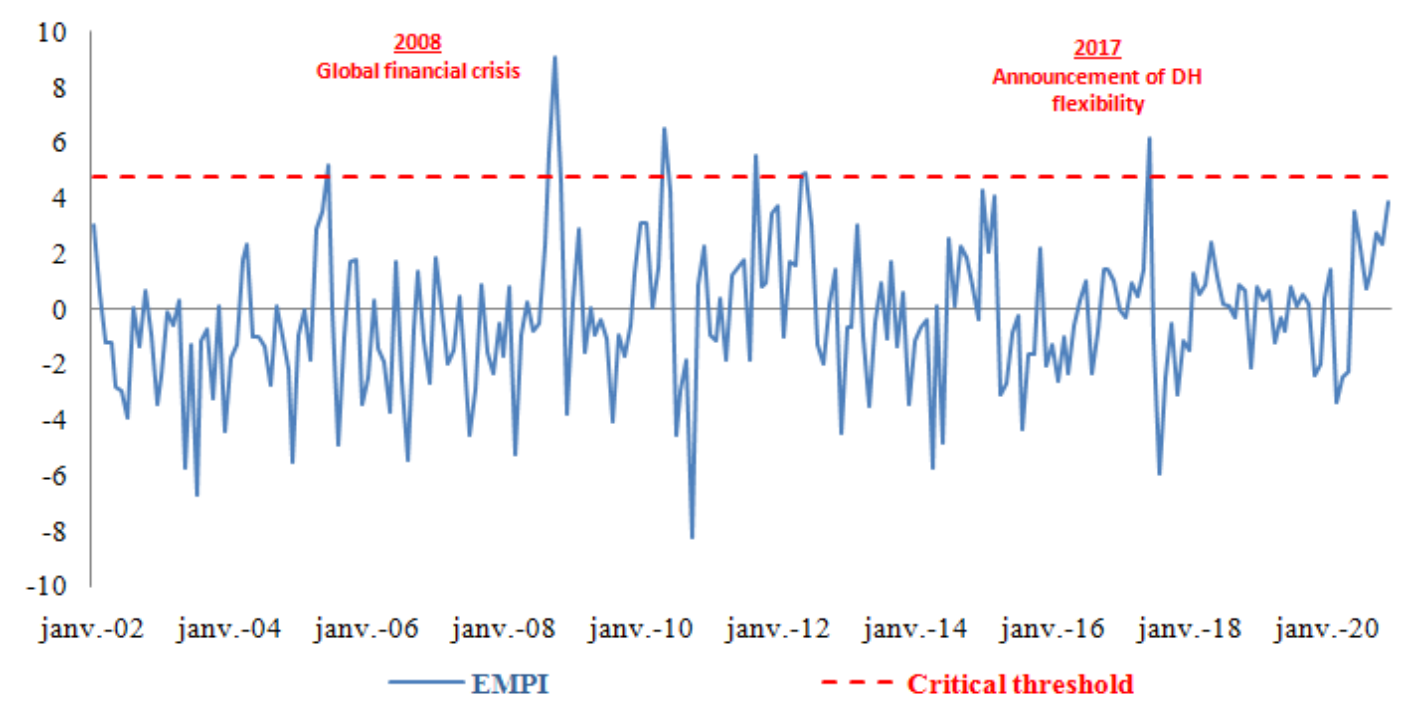

Source: Authors' calculations

Figure 1: Evolution of the EMP crisis index for the case of Morocco

The analysis of the monthly time series of the EMPI, during the period January 2002-April 2020, revealed 6 periods marked by the pressure on the Moroccan foreign exchange market:

$\checkmark 1^{\text {st }}$ period (June 2005): characterized by a depreciation of the Dirham against the Dollar by $3.5 \%$ and a drop in foreign exchange reserves by 2.4\% in April 2005.

$\checkmark 2^{\text {nd }}$ period (September-October 2008): which coincided with the onset of the global financial crisis. The Dirham recorded an average depreciation of more than $4 \%$ and foreign exchange reserves declined by 6\%, from 200 billion Dirhams in August 2008 to 189 billion Dirhams in October 2008.

$\checkmark 3^{\text {rd }}$ period (May 2010): which experienced a depreciation of $4.8 \%$ in the nominal exchange rate and a decline of $5 \%$ in foreign exchange reserves.

$\checkmark 4^{\text {th }}$ period (September 2011): where pressure is particularly due to the effect of a $3 \%$ drop in foreign exchange reserves and a $4 \%$ depreciation of the Dirham against the Dollar.

$\checkmark 5^{\text {th }}$ period (May-June 2012): during which the Dirham depreciated by more than $2 \%$ and foreign exchange reserves knew a cumulative decline of almost $8 \%$.

$\checkmark 6^{\text {th }}$ period (May-June 2017): characterized by the effects of the announcement by the Moroccan authorities to switch to a more flexible exchange rate regime. Since then, the Dirham came under pressure amid fears expressed by banks and importers who sought to protect themselves against a possible depreciation of the national exchange rate. Meanwhile, the decrease in foreign exchange reserves, which began to accelerate since April 21, continued in May to reach its lowest level at 31 billion Dirhams on June 13, 2017. 
Based on the results of the previous analysis, it can be concluded that the EMPI has particularly shown significant increases in separate years: 2002, 2006, 2008, 2011 and 2017. Indeed, they correspond to the periods when Morocco experienced foreign exchange crises, which occurred mainly as a result of significant fluctuations in both net international reserves (a significant drop in the NIR) and the nominal exchange rate (a remarkable appreciation of the NIR).

Furthermore, the main crisis that Morocco has known according to the EMPI is that of October 2008, when the Dirham was devalued by 7\%. Likewise, foreign exchange reserves fell by 6\%, from 200 billion Dirhams in August 2008 to 189 billion Dirhams in October 2008.

Clearly, it appears that the combined effect of an appreciation in nominal exchange rate and a significant reduction in international reserves makes the Moroccan economy particularly vulnerable to an exchange market crisis.

The graph below illustrates some scenarios to be avoided in order to keep safe against a possible crisis or pressure on the Moroccan foreign exchange market.

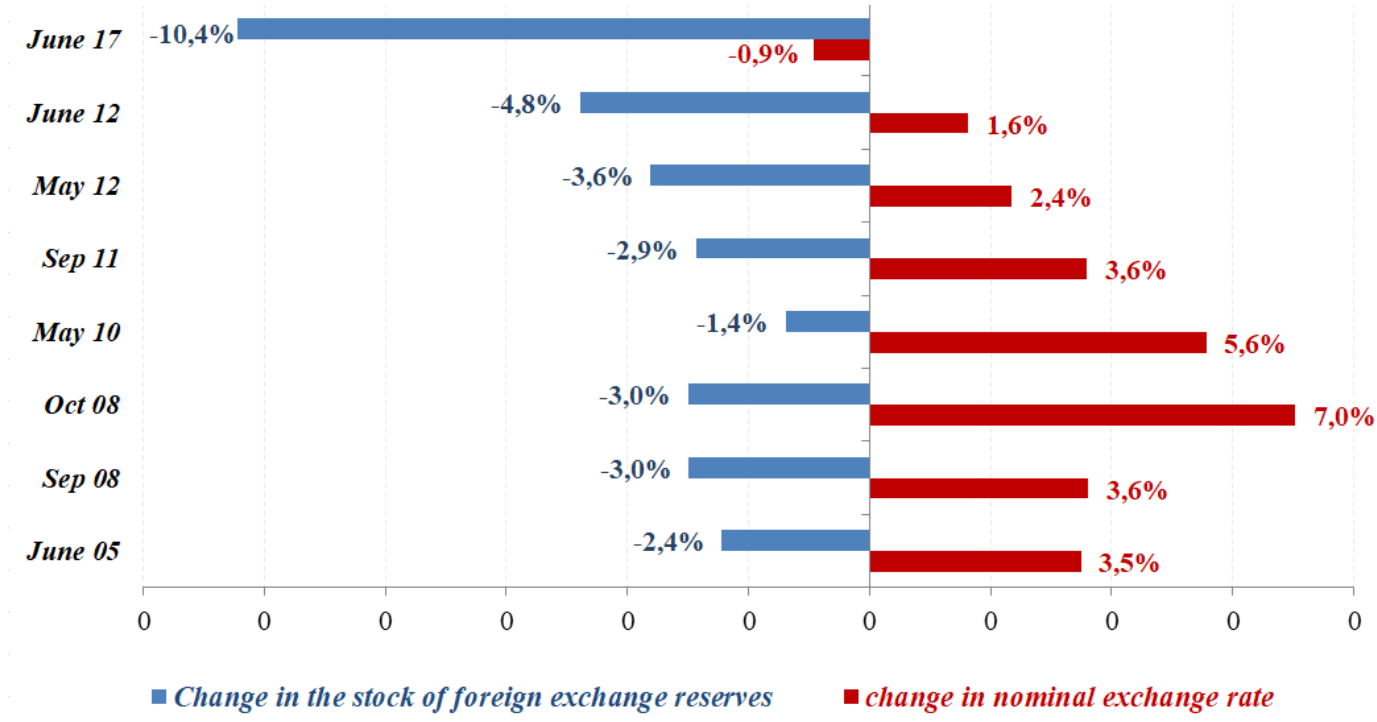

Source: Authors' calculations

Figure 2: Scenarios leading to pressure on the Moroccan foreign exchange market

Taking into account the fact that no crisis has been revealed by the EMPI in the last two years, it can be concluded that the policy of gradual flexibility of the exchange rate regime, which has been implemented since January 2018, has played a crucial role in this respect. Consequently, this reform has undoubtedly eased the pressure on the exchange rate by making the Moroccan economy more resilient and less vulnerable to external shocks. 


\section{The probability of a currency crisis outbreak}

\subsection{Method to estimate the probability of a currency crisis}

Once the EMPI crisis index is calculated, we proceed to estimate the probability that a currency crisis occurred in Moroccan economy. This requires setting up a logistic probabilistic model ${ }^{5}$ based on a set of macroeconomic indicators reflecting the competitiveness of Morocco's external sector.

The objective is to empirically identify the warning indicators that could notice a possible currency crisis. The idea is to define the vulnerability factors to currency crises, beyond the determinants of the foreign exchange market, by integrating other explanatory variables related to the external sector.

The Logit model defines the probability of the event $y=1$ (crisis) as the value of the distribution function of the logistic law at the point $x_{i} \beta$ :

$$
P_{i}=P\left(y_{i}=1 / x\right)=F\left(x_{i} \beta\right)
$$

It admits respectively as function of distribution and density:

$$
\begin{aligned}
& F\left(x_{i} \beta\right)=\frac{e^{x_{i} \beta}}{1+e^{x_{i} \beta}} \quad \text { or } \quad F\left(x_{i} \beta\right)=\frac{1}{1+e^{-x_{i} \beta}} \\
& f\left(x_{i} \beta\right)=\frac{e^{x_{i} \beta}}{\left(1+e^{x_{i} \beta}\right)^{2}}
\end{aligned}
$$

Where: $x_{i}=(x i 1, x i 2, \ldots, x i k)$ is the vector of explanatory variables for each $\mathrm{i}=1,2, \ldots$, n. $\beta^{\prime}=\left(\beta_{1}, \beta_{2}, \beta_{3}, \ldots, \beta_{k}\right)^{\prime}$ corresponds to the vector of parameters.

In order to model the variable "CRISIS" for the case of Morocco, quarterly data are used covering the period starting from Q1-2001 to Q4-2019. We have retained, in accordance with several studies cited in the empirical literature, some key variables of the external sector, in particular:

$\checkmark$ VAR_FXR: Change in the stock of foreign exchange reserves;

$\checkmark$ CAB_BOP: Current account deficit of the balance of payments as a percentage of GDP;

$\checkmark$ MIS_REER: Misalignment of the REER(already estimated in the first part of this paper);

$\checkmark$ VAR_EXP: Change in exports of goods and services.

\footnotetext{
${ }^{5}$ Logit model of which "CRISIS" is the binary variable explained
} 


\subsection{Results of the Logit model}

The results obtained by the Logit model show that:

$\checkmark$ While exerting pressure on the foreign exchange market, distortions in the real exchange rate increase the probability of a currency crisis outbreak.

Consequently, the Moroccan economy is more vulnerable to a currency crisis when the value of the Dirham is under/over valued.

$\checkmark$ As far as the current account of the balance of payments is concerned, a widening deficit of it can be perceived as a sign of vulnerability and can also contribute to an increase of the EMPI. The Logit model reveals that a notable worsening of the current account deficit during the period t- 1 tends to increase the probability of occurrence of an exchange rate crisis during the period t.

$\checkmark$ In addition, any improvement in exports could normally reduce the vulnerability of any country to a currency crisis. But in our case, it appears that the increase in Moroccan exports seems to have little or no impact on EMPI( $0.2 \%$ only). One could conclude, in this regard, that the change in exports cannot be considered as an early warning indicator to predict the pressures on the Moroccan exchange market.

$\checkmark$ As for the impact of the last warning indicator, the change in foreign exchange reserves, it seems that an improvement lagged by only one quarter would be sufficient to have a positive impact on the EMPI. It therefore plays a key role in the stability of the foreign exchange market by reducing Morocco's vulnerability to a crisis on this market.

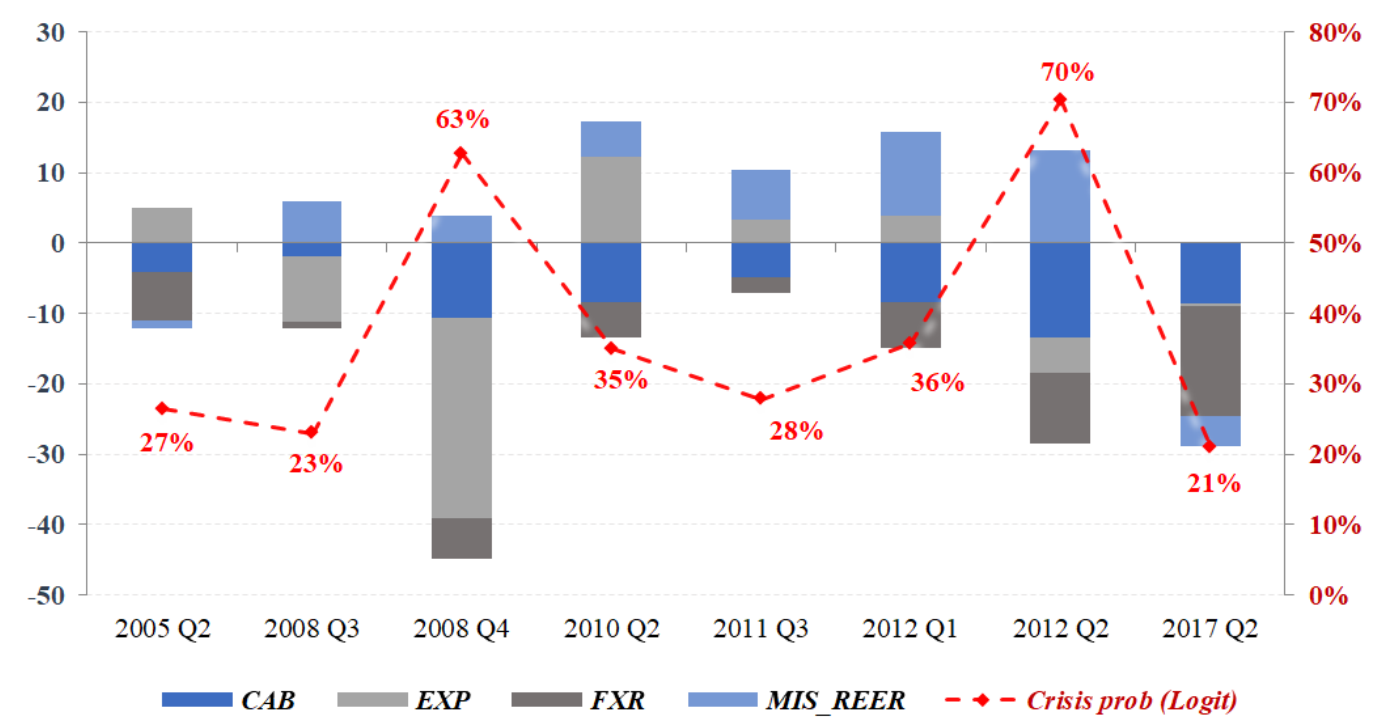

Source: Office des Changes, Bank Al Maghrib, Authors' calculations

Figure 3: Contributions of external fundamentals to the onset of crises (Changes in \%) 
It is conspicuous from the previous results that the high frequency of a currency crisis occurrence is attributable to the deterioration of the main external sector indicators, except the changes in exports.

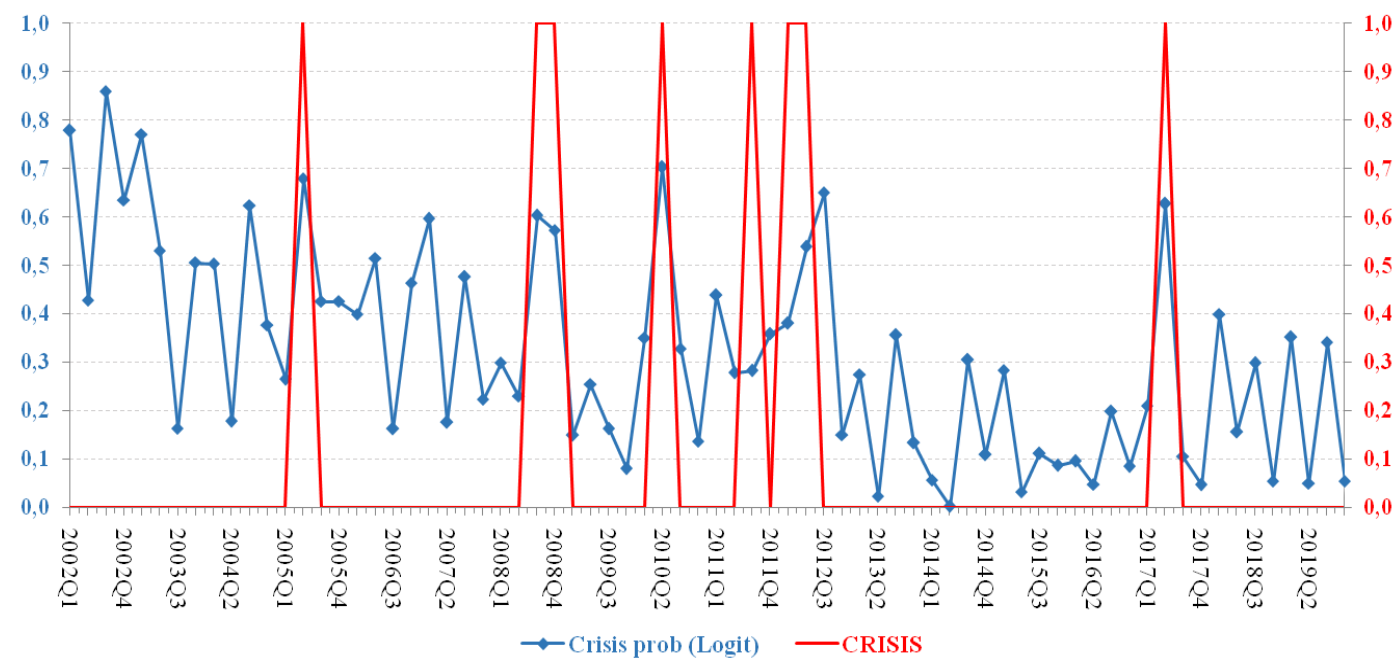

Source: Authors' calculations

Figure 4: Probability of crisis according to the Logit regression

The Logit model predicted 8 crisis periods with significantly high probabilities. Among these 8 periods we can distinguish 3 which have been predicted with more intensity, in particular in the second half of 2008, the first half of 2012 and the second quarter of 2017.

The analysis of the graph above shows that after the first exchange rate crisis recorded on the exchange market in the first quarter of 2002, the rate of crises accelerated between 2008 and 2012 due particularly to the 2008 global financial and economic crisis effects. After the last underperformance of the exchange market observed in June 2017, the probability of an exchange crisis has sharply decreased thanks to the good performance of the external sector during this period.

In other words, the Moroccan foreign exchange market was under pressure in the fourth quarter of 2008, with a probability of crisis approaching 63\%. This unfavorable situation is mainly explained by the worsening of the current account deficit of $10.7 \%$ induced by the highly drop in exports by $28 \%$ and the fall in foreign exchange reserves by $6 \%$.

As for the crises of the first and second quarters of 2012, they can be explained by the record levels of the current account deficit of $-8.3 \%$ and $-13.5 \%$ respectively, the sudden fall in reserves at $-7 \%$ and $-10 \%$ and the REER overvaluation of $12 \%$ and $13 \%$.

Regarding the crisis reported in the second quarter of 2017, it results from a deterioration of the current account balance deficit (-9\%), a drastic reduction of reserves $(-16 \%)$ and a depreciation of the Dirham by more than $4 \%$. 


\subsection{Pressure on Moroccan foreign exchange market from the end of the year 2020}

Under the effect of the global crisis due to the unprecedented spread of COVID-19 all over the world, the main components of Morocco's external sector should be considerably deteriorated according to the expected decline in foreign demand addressed to our country. Therefore, the national exchange market is likely to be under pressure in the near future. That's why it is of great importance to predict what the exchange market would be from the end of 2020 particularly.

According to the Logit model, the EMPI predictions show that the pressure on foreign currencies demand should remain under control during the year 2020 and, therefore, the Dirham would not be affected by speculative attacks.

In fact, the crisis index revealed no risks or pressures on the exchange rate during the year 2020. This favorable situation is the result of the measures carried out by Morocco, in particular the drawdown from the LPL and the mobilization of other external financing, which will certainly reduce the impact of the current health crisis and maintain the foreign exchange reserves at a relative comfortable level, and hence ensuring a certain stability of the Moroccan exchange market.

On the one hand, the Logit model also indicated that the probability of a speculative attack on Dirham in the first nine months of 2020 would remain significantly low. On the other hand, the first signs of pressure on exchange market should be apparent particularly in the fourth quarter of 2020 , with a crisis probability of roughly $63 \%$.

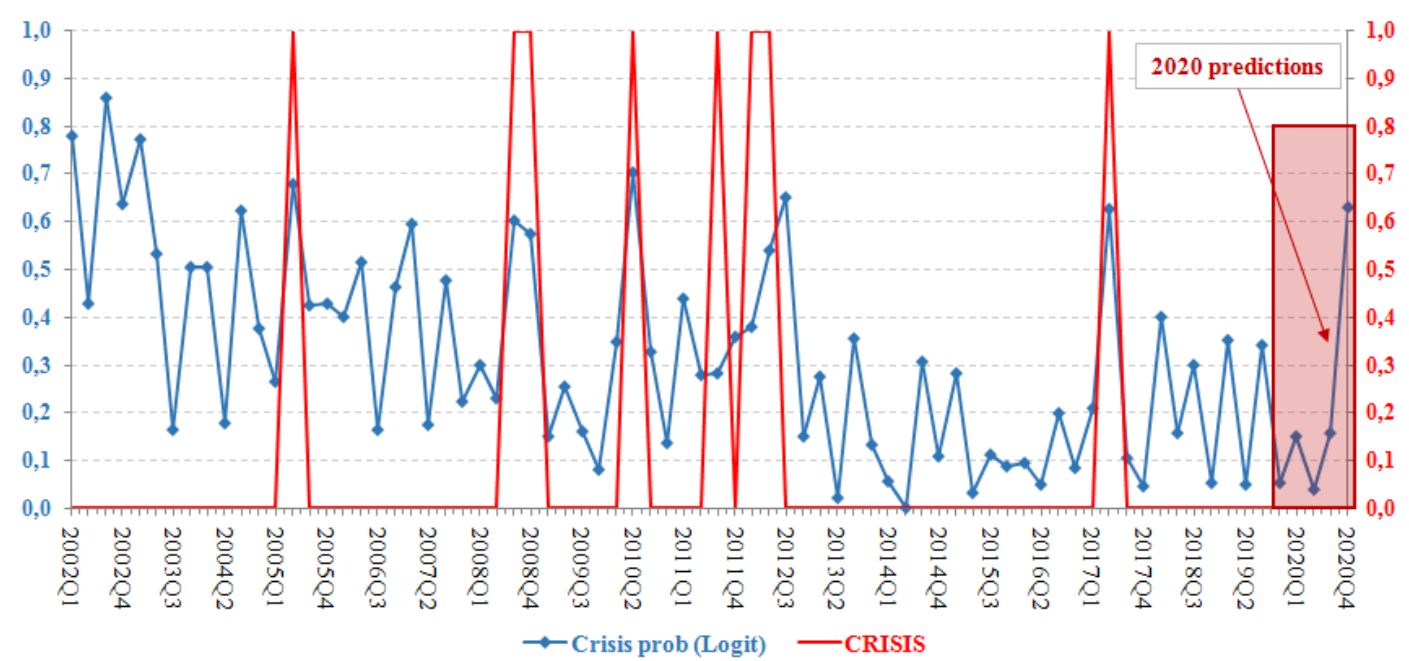

Source: Authors' calculations

Figure 5: Probability of crisis according to the Logit regression 


\section{Conclusion}

The main conclusion of this article is that the EMP crisis index did not signal any currency crisis during the last two years 2018 and 2019. Accordingly, it is obvious that the reform of the exchange rate regime towards a more flexible exchange rate, entered into effect at the beginning of 2018, has contributed significantly to moderate pressure on the exchange market and to make the Moroccan economy progressively more resistant to external shocks.

Given the results of the Logit probabilistic model and the uncertainties related to the current economic and financial crisis resulting from COVID-19, it is very likely that Morocco's exchange market could experience a speculative attack from the $4^{\text {th }}$ quarter of 2020, with a probability of onset of crisis exceeding 60\%. In this regard, it would be appropriate for the national authorities to implement preventive measures to avoid a possible crisis in this market, particularly by the acceleration of the pace of reform of the exchange rate regime which has shown, according to the results of this study, its efficiency in this context of systemic crisis. Also, it is necessary to reckon the importance of diversifying the sources of foreign currencies in order to reduce the dependence of the Moroccan economy on traditional sources such as tourism, remittances of Moroccans residing abroad and external debt. The big project for designing a new national development model, showing a certain delay due to the national and international context surrounded by uncertainties, constitutes an important opportunity for decision-makers to work on issues relating to the external sector, in particular in exchange market, and their effects on the macroeconomic framework.

This type of study teaches us clearly that Morocco must double its efforts, by force of circumstances, while taking into account the constraints of the current economic conjuncture, characterized in particular by the perverse effects of the current systemic crisis. Moreover, in a world where trade has become increasingly globalized and international competition is very tough, it is of great importance to improve our competitive advantages, particularly on the economic, institutional, political and cultural levels. 


\section{References}

[1] L. Girton, D. Roper. (1977). "A Monetary Model of Exchange Market Pressure Applied to the Postwar Canadian Experience", The American Economic Review, 67(4), 537-548.

[2] Ammar Hamad Khalaf. (2018). "Foreign exchange market pressure index and monetary policy in Iraq". Economic Annals, Volume LXIII, No. 219.

[3] G. Al-Assaf. (2017). “An Early Warning System for Currency Crisis: A Comparative Study for the Case of Jordan and Egypt". International Journal of Economics and Financial Issues 7(3), 43-50.

[4] Burnside, Craig, Martin Eichenbaum, and Sergio Rebelo. (2001)."Prospective Deficits and the Asian Currency Crisis", Journal of Political Economy, vol. 109, 1155-1197.

[5] Chang, Roberto, and Andres Velasco. (2001)."A Model of Financial Crisis in Emerging Markets," Quarterly Journal of Economics, vol. 116, 489-517.

[6] A. Deressa.(2005)."Exploring the Link Between Exchange Market Pressure and Monetary Policy in Ethiopia". Ethiopian Journal of Economics, 14(2), 3353.

[7] P. Robert and M. Garber.(1984).“Collapsing Exchange-Rate Regimes,” Journal of International Economics, vol. 17, 1-13.

[8] L. Graciela and M. Reinhart.(1999). "The Twin Crises: The Causes of Banking and Balance-of-Payments Problems". American Economic Review, vol. 89, 473-500.

[9] P. Krugman. (1979). “A Model of Balance-of-Payments Crises,” Journal of Money, Credit, and Banking, vol. 11, 311-325.

[10] P. Krugman, (1999). "Balance Sheets, The Transfer Problem, and Financial Crises," International Tax and Public Finance, vol. 6, 459-472.

[11] A. Miksjuk, S. Ouliaris, and M. Pranovich. (2015). "The Game of Anchors: Studying the Causes of Currency Crises in Belarus". IMF Working Paper $15 / 281$.

[12] Morris, Stephen, and Hyun Song Shin. (1998).“Unique Equilibrium in a Model of Self-Fulfilling Currency Attacks”. American Economic Review, 88(3), 58797.

[13] Obstfeld, Maurice.(1994). "The Logic of Currency Crises," NBER WP 4640.

[14] Obstfeld, Maurice. (1996). "Models of Currency Crises with Self-Fulfilling Features," European Economic Review, vol. 40, 1037-1047. 